\title{
Annotations
}

\section{The fetus of the diabetic mother: growth and malformations}

Since Pedersen ${ }^{1}$ put forward the hyperglycaemia hyperinsulinaemia hypothesis as an explanation of the aetiology of diabetic fetal anomalies the care of the pregnant diabetic patient and her fetus has greatly improved. If the diabetes of the mother has been well controlled during pregnancy, the newborn child is not grossly overweight, the perinatal morbidity is low, and hypoglycaemia and other neonatal complications can be successfully treated. Despite these improvements, however, there has been no change in the incidence of malformations in these neonates, and this remains the greatest problem in the management of the pregnant diabetic woman. ${ }^{2}$

In studies of the effects of diabetes on the fetus and malformations, experimental animals have been widely used. Many rodent models of diabetic pregnancy have, however, several shortcomings. These include: retardation of fetal growth and reduction rather than increase of birthweight, ${ }^{3-5}$ hyperinsulinaemia does not occur ${ }^{4}$ and the islets of Langerhans are hypotrophic rather than hypertrophic. ${ }^{6}$ In one specific Sprague-Dawley rat substrain, however, diabetes during pregnancy causes not only retardation of fetal growth but also a high incidence of skeletal malformations not seen in normal pregnancy. ${ }^{7}$ Insulin treatment of the diabetic rats almost abolishes retardation of growth and malformations, but withdrawal of insulin during short specific periods early in pregnancy is enough to induce malformations. ${ }^{8}$ Several parallels with human diabetic pregnancy are evident: firstly there - is retardation of growth in early human diabetic pregnancy, ${ }^{9}$ which is associated with an increased incidence of malformtions in the neonate. ${ }^{10}$ Moreover, poor metabolic control early in pregnancy during the sensitive period of organogenesis is also associated with an increased risk of malformations in human pregnancy. ${ }^{11}$

It seems therefore that a suitable experimental model for the study of teratogenesis during diabetic pregnancy is available. In this substrain of Sprague-Dawley rats that is prone to fetal malformations, there is the interaction between genetic factors and the metabolic derangement of diabetes that is necessary for the induction of skeletal malformations, ${ }^{12}$ but the nature of the genetic predisposition is not yet clear. It is, however, noteworthy that diabetes exacerbates changes in proteoglycan metabolism in cartilage that are more severe in this substrain than in other SpragueDawley strains. ${ }^{13}$ Whether malformations in human diabetic pregnancy are linked to genetic markers in the mother or fetus, or both, is open to question.

To explore further how diabetes retards fetal growth and causes malformations, a model system more controllable than an intact animal would be helpful. Tissue culture of whole rat or mouse embryos seems promising in this respect, because the effect of a single substance or metabolite can be measured. ${ }^{14}$ Such studies have shown that high plasma glucose concentrations and ketone bodies, alone or in combination, induce retardation of growth and malformations in vitro, in both strains of rats that are prone to malformation and those that are not. ${ }^{1215}$ Plasma glucose concentrations in the hypoglycaemic range have also been shown to induce malformations in vitro. ${ }^{16}$ These and other observations have led to the hypothesis that disturbances of the glycolytic flux at a critical developmental stage (and in the absence of other major alternative pathways of metabolism) cause malformations. ${ }^{15} 17$ Abnormal glucose metabolism, however, may not explain all malformations, ${ }^{18}$ and it does seem plausible that disturbances in the supply of other nutrients such as amino acids and lipids would effect growth and morphogenesis by altering the availability of building blocks for proteins and membranes, or by effects on energy metabolism, or both. ${ }^{19}$

The close association between retardation of growth and teratogenesis has focused attention on the regulation of growth of embryonal cells. In a preliminary study of chondrocyte differentiation of cells in vitro from the particular substrain of rat that is prone to malformations, an inhibition of chondrocyte replication was noted in the presence of ketone bodies or high glucose concentrations. Moreover, chondrocytes obtained from locations at which skeletal malformations have been observed to occur in vivo were more sensitive to the inhibitory 
effect of glucose.$^{20}$ This approach appears promising for the future study of diabetic teratogenesis, and the culture method may provide a screen for putative teratogens.

Many investigations of the regulation of embryonal and fetal growth have not directly addressed the question of teratogenesis but rather studied basal requirements for cellular growth and replication. It seems that prenatal growth is dependent on a complex interaction between the supply of nutrients, circulating hormones, and polypeptide growth factors that act locally. ${ }^{21}$ Of the circulating hormones, human placental lactogen has attracted most attention. Synthesised and secreted by the placenta and present in high concentrations in the maternal circulation, it can also be found in appreciable concentrations in fetal blood. ${ }^{21}$ Human placental lactogen stimulates replication of human fetal cells in vitro, and this effect is partly mediated by somatomedins and insulin like growth factors. ${ }^{22}$ The insulin like growth factors are produced by a number of fetal tissues and are thought to act locally, at or near their site of production. ${ }^{23}$ To achieve the optimal effects from the circulating and local growth factors an adequate intracellular supply of nutrients is necessary. Uptake and metabolism of nutrients in the cells is stimulated by insulin, and it has been suggested that this hormone interacts with low molecular weight nutrients to provide an anabolic enviroment that encourages growth. ${ }^{24}$ The complicated network of interactions also includes stimulation of insulin secretion in the fetus by nutrients and human placental lactogen and stimulation of human placental lactogen production by insulin. ${ }^{25-27}$ The experimental findings are paralleled by the recent clinical observation that maternal human placental lactogen concentrations correlate with the size of the baby at birth and hence, by inference, with fetal growth. ${ }^{28}$ It is possible, but not yet proved, that a high production of human placental lactogen is also reflected in the fetal circulation. Moreover, birth weight also varies with differences within the normal range of glucose tolerance. ${ }^{28}{ }^{29}$ Mothers with slow, although not diabetic, disposal of glucose and who thus have wider ranges of blood glucose concentration, transfer more glucose (and perhaps also more of other nutrients) to the fetus, which at birth is larger but of normal adiposity. ${ }^{28}$ To benefit from such a rich supply of nutrients the fetus would need a parallel increase in its own insulin secretion. This may indeed be the case because the human fetal B cell is more sensitive to glucose in earlier developmental stages than $h . s$ hitherto been generally accepted. ${ }^{27}$

Most investigations of the regulation of growth in vitro have been performed with cells taken from human fetuses early in the second trimester, and it is uncertain whether the regulatory mechanisms are relevant for the early embryo. In rodents, however, insulin like growth factors, insulin, and their respective receptors are present early in development, ${ }^{30} 31$ and some evidence that they have a role in regulation of growth has been presented. ${ }^{32}$ By combining the considerable knowledge on the actions of hormones and growth factors with that on experimental models of teratogenesis outlined above, new insights into embryonal growth and teratogenesis would be gained. ${ }^{33}$ Meanwhile, excellent control of blood glucose concentrations before conception is still the best advice for the diabetic woman contemplating pregnancy.

This work was supported by the Swedish Diabetes Association, the Juvenile Diabetes Foundation (grant 185544) and the Swedish Medical Research Council (grants 12X-109 and 12X-7475).

\section{References}

1 Pedersen, J. Weight and length at birth of infants of diabetic mothers. Acta Endocrinol 1954;16:330-42.

2 Olofsson P, Liedholm H, Sartor G, Sjöberg N-O, Svenningsen NW, Ursing D. Diabetes in pregnancy. A 21-year Swedish material. Acta Obstet Gynecol Scand 1984;122(suppl):1-62.

3 Endo A. Teratogenesis in diabetic mice treated with alloxan prior to conception. Arch Environ Health 1966;12:492-500.

${ }^{4}$ Eriksson U, Andersson A, Efendić S, Elde R, Hellerström C. Diabetes in pregnancy: effects on the foetal and newborn rat with particular regard to body weight, serum insulin concentration and pancreatic contents of insulin, glucagon and somatostatin. Acta Endocrinol 1980;94:354-64.

5 Brownscheidle CM, Davis DL. Diabetes in pregnancy: A preliminary study of the pancreas, placenta, and malformations in the BB Wistar rat. Placenta 1981;3(suppl):203-16.

${ }^{6}$ Eriksson U, Swenne I. Diabetes in pregnancy; growth of the fetal pancreatic B-cell in the rat. Biol Neonate 1982;42:239-48.

${ }^{7}$ Eriksson UJ, Dahlström VE, Styrud J. Metabolically determined teratogenesis: malformations and maternal diabetes. Biochem Soc Trans 1985;13:79-82.

${ }^{8}$ Eriksson UJ, Dahlström VE, Hellerström C. Diabetes in pregnancy: skeletal malformations in the offspring of diabetic rats after intermittent withdrawal of insulin early in gestation. Diabetes 1983;32:1141-5.

" Pedersen JF, Mølsted-Pedersen L. Early growth retardation in diabetic pregnancy. Br Med J 1979;i:18-9.

${ }^{10}$ Pedersen JF, Mølsted-Pedersen L. Early fetal growth delay detected by ultrasound marks increased risk of congenital malformation in diabetic pregnancy. Br Med $J$ 1981;283:269-71.

11 Miller E, Hare JW, Cloherty JP, et al. Elevated maternal hemoglobin $A_{l c}$ in early pregnancy and major congenital anomalies in infants of diabetic mothers. $N$ Engl $J$ Med 1981;304:1331-4.

12 Eriksson UJ. Importance of genetic predisposition and maternal environment for the occurence of congenital malformations in the offspring of diabetic rats. Teratology 1988;37:365-74.

13 Eriksson UJ, Unger E, Kjellén L. Decreased levels of high molecular weight cartilage proteoglycans in diabetic rats of a malformation-prone strain. Diabetologia 1986;29:534A.

14 Sadler TW, Horton WE, Warner CW. Whole embryo culture: a screening technique for teratogens? Teratogenesis Carcinog Mutagen 1982;2:243-53.

15 Horton WE, Sadler TW. Effects of maternal diabetes on early 
embryogenesis. Alterations in morphogenesis produced by the ketone body, $\beta$-hydroxy-butyrate. Diabetes $1983 ; 32: 610-16$.

16 Sadler TW, Hunter III ES. Hypoglycemia: how little is too much for the embryo? Am J Obstet Gynecol 1987;157:190-3.

17 Freinkel N, Lewis NJ, Akazawa S, Roth SI, Gorman L. The honeybee syndrome-implications for the teratogensis of mannose in rat-embryo culture. $N$ Engl J Med 1984;310:223-30.

${ }^{18}$ Mills JL, Knopp RH, Simpson JL, et al. Lack of relation of increased malformation rates in infants of diabetic mothers to glycemic control during organogenesis. N Engl J Med 1988; 318:671-6.

19 Kalkhoff RK, Kandaraki E, Morrow PG, Mitchell TH, Kelber S, Borkowf HI. Relationship between neonatal birth weight and maternal plasma amino acid profiles in lean and obese non-diabetic women and in type I diabetic pregnant women. Metabolism 1988;37:234-9.

${ }^{20}$ Styrud J, Unger E, Eriksson UJ. Development of fetal prechondrocytes in vitro is altered by increase levels of $D$-glucose and $\beta$-hydroxybutyrate. Diabetologia 1987;30:586A.

${ }^{21}$ Milner RDG, Hill DJ. Interaction between endocrine and paracrine peptides in prenatal growth control. Eur J Paediatr 1987; 146:113-22.

${ }^{22}$ Hill DJ, Crace CJ, Milner RDG. Incorporation of $\left({ }^{3} \mathrm{H}\right)$ thymidine by isolated fetal myoblasts and fibroblasts in response to human placental lactogen (HPL): Possible mediation of HPL action by release of immunoreactive SM-C. J Cell Physiol 1985;125:337-44.

${ }^{23}$ D'Ercole AJ, Applewhite GT, Underwood LE. Evidence that somatomedin is synthesized by multiple tissues in the fetus. Dev Biol 1980;75:315-28.

24 Hill DJ, Milner RDG. Insulin as a growth factor. Pediatr Res 1985;19:879-86.

${ }^{25}$ Swenne I, Hill DJ, Strain AJ, Milner RDG. Effects of human placental lactogen and growth hormone on the production of insulin and somatomedin C/insulin-like growth factor I by human fetal pancreas in tissue culture. $J$ Endocrinol 1987;113:297-303.
${ }^{26}$ Bhaumick B, Dawson EP, Bala RM. The effects of insulin-like growth factor-I and insulin on placental lactogen production by human term placental explants. Biochem Biophys Res Commun 1987; 144:674-82.

27 Otonkoski T, Andersson A, Knip M, Simell O. Maturation of insulin response to glucose during human fetal and neonatal development. Studies with perfusion of pancreatic islet like cell clusters. Diabetes 1988;37:286-91.

${ }^{28}$ Langhoff-Roos J. Determinants of infant birth weight at term. A study of hereditary, nutritional and metabolic factors. Comprehensive Summaries of Uppsala Dissertations from the Faculty of Medicine 1987;115:1-47.

29 Tallarigo L, Giampietro O, Penno G, Micolli R, Gregori G, Navalesi R. Relation of glucose tolerance to complications of pregnancy in nondiabetic women. $N$ Engl J Med 1986;315: 989-92.

${ }^{30}$ Smith EP, Sadler TW, D'Ercole AJ. Somatomedins/insulin-like growth factors, their receptors and binding proteins are present during mouse embryogenesis. Development 1987;101:73-82.

${ }^{31}$ Kakita K, Giddings SJ, Rotwein PS, Permutt MA. Insulin gene expression in the developing rat pancreas. Diabetes 1983; 32:691-6.

${ }^{32}$ Liu L, Russel SM, Nicoll CS. Growth and differentiation of transplanted rat embryos in intact, diabetic and hypophysectomized hosts: Comparison with their growth in situ. Biol Neonate 1987;52:307-16.

33 Hill DJ, Strain AJ, Milner RDG. Growth factors in embryogenesis. In: Clarke JR, ed. Oxford reviews of reproductive biology. No 9. Oxford: Oxford University Press; 1988, (in press).

I SWENNE

Department of Medical Cell Biology, Biomedicum, $P$ O Box 571, S-571 23 Uppsala, Sweden 